\title{
Investigations into a novel method for atmospheric polycyclic aromatic hydrocarbon monitoring
}

\author{
Patricia B.C. Forbes ${ }^{\mathrm{a}, \mathrm{b}, *}$, Egmont R. Rohwer ${ }^{\mathrm{b}}$ \\ ${ }^{a}$ Natural Resources and the Environment, Council for Scientific and Industrial Research, PO Box 395, Pretoria 0001, South Africa \\ ${ }^{\mathrm{b}}$ Department of Chemistry, Faculty of Natural Science, University of Pretoria, Pretoria 0002, South Africa \\ A novel method for rapid analysis of atmospheric PAHs by laser induced fluorescence allows for more detailed trend determinations.
}

\section{A R T I C L E I N F O}

\section{Article history:}

Received 21 November 2008

Accepted 4 March 2009

\section{Keywords:}

Polycyclic aromatic hydrocarbons

Laser induced fluorescence

Polydimethylsiloxane

Atmospheric monitoring

Photodegradation

\begin{abstract}
A B S T R A C T
A novel analytical method for atmospheric polycyclic aromatic hydrocarbons (PAHs) was developed based on laser induced fluorescence (LIF) of samples on quartz multi-channel polydimethylsiloxane traps. A tunable dye laser with a frequency doubling crystal provided the excitation radiation, and a double monochromator with a photomultiplier tube detected emitted fluorescence. The method allowed for the rapid ( $<5 \mathrm{~min}$ ), cost effective analysis of samples. Those yielding interesting results could be further analysed by direct thermal desorption-gas chromatography-mass spectrometry (TD-GC-MS, with limits of detection of $\sim 0.3 \mathrm{ng} \mathrm{m}^{-3}$ ), as photodegradation was minimal ( $<10 \%$ over $5 \mathrm{~min}$ irradiation). Small amounts of naphthalene photodegradation products identified by TD-GC-MS after $>15$ min irradiation, included phenol, benzyl alcohol and phthalic anhydride. Without any signal optimization, a LIF detection limit of $\sim 1 \mu \mathrm{g} \mathrm{m}^{-3}$ was established for naphthalene using a diffusion tube (diffusion rate of $2 \mathrm{ng} \mathrm{s}^{-1}$ ) and $292 \mathrm{~nm}$ excitation.
\end{abstract}

() 2009 Elsevier Ltd. All rights reserved.

\section{Introduction}

Polycyclic aromatic hydrocarbons (PAHs) are pollutants of environmental concern as a result of their potential toxicity. They are produced upon the incomplete combustion of organic matter, therefore important sources in developing countries include biomass burning, vehicular emissions and indoor wood burning for space heating and cooking purposes.

The spectroscopic features of PAHs include large absorption cross-sections and high fluorescence quantum yields (Song et al., 2003), thus fluorescence has been used as a means of detection of these compounds in applications such as high performance liquid chromatography for many years. Quantitative analysis of vapour phase PAHs at elevated temperatures by laser induced fluorescence (LIF) utilizing an excitation wavelength of $337.1 \mathrm{~nm}$ has been reported (Allain et al., 2003; Chi et al., 2001). Similarly, pyrene in cigarette smoke has been determined by LIF based on fiber optics with time resolution to enhance sensitivity (Song et al., 2003), although distortion of the fluorescence spectra in the fibres may

\footnotetext{
* Corresponding author. Natural Resources and the Environment, Council for Scientific and Industrial Research, PO Box 395, Pretoria 0001, South Africa. Tel.: +27 12841 3031; fax: +27 128412689.

E-mail addresses: pforbes@csir.co.za (P.B.C. Forbes), egmont.rohwer@up.ac.za (E.R. Rohwer).
}

occur (Kotzick and Niessner, 1996). In order to enhance selectivity of single wavelength analysis of mixtures of PAHs, deconvolution algorithms have been employed in this regard, although usually only mixtures of $\leq 3$ components are effectively treated in this manner (Knorr and Harris, 1981; Kotzick and Niessner, 1996).

LIF coupled with fiber optics has also been employed in the determination of PAHs in other environmental matrices, such as soil and sediments (Grundl et al., 2003) and two-photon excitation fluorescence microscopy, which utilized a pulsed solid state laser, has been used to visualize the fate and behaviour of PAHs within living vegetation (Wild et al., 2005, 2007).

Naphthalene has been detected in air using the Fluorescent Assay by Gas Expansion (FAGE) technique, where the gas phase analyte is excited by laser pulses at $308 \mathrm{~nm}$ passing through a detection chamber (Martinez et al., 2004). Quenching of naphthalene fluorescence by $\mathrm{N}_{2}$ and $\mathrm{O}_{2}$ in the air sample was reported.

Multi-channel polydimethylsiloxane (PDMS) traps have been developed for semi-volatile organic air pollutant monitoring with TD-GC-MS analysis (Ortner and Rohwer, 1996). Packed bed PDMS traps (Baltussen et al., 1997) and mixed bed traps containing PDMS foam, PDMS particles and Tenax TA (Wauters et al., 2008) have also been tested in this application. Commercial PDMS solid-phase microextraction (SPME) fibres have been reported in the sampling of airborne particulate matter, such as that arising from diesel vehicular exhausts, followed by GC-MS analysis (Koziel et al., 
2001), and in single-particle analysis by Raman spectroscopy (Odziemkowski et al., 2001). SPME utilizing a $50 \mu \mathrm{m}$ coating of PDMS on a glass fiber rod coupled with LIF detection has recently been tested for $\mathrm{PAH}$ determinations in sediment pore water (Hawthorne et al., 2008).

Many current analytical methods for atmospheric PAH determinations are time consuming and require the use of solvent extraction of samples, which may limit the widespread sampling and analysis of PAH samples for spatial and temporal trend determination. We have therefore developed a method which will allow for the rapid analysis of samples for the presence of PAHs, prior to comprehensive, quantitative analysis, if required. Air is sampled onto a multi-channeled silicone rubber trap (Ortner, 1994), in which the PDMS serves as a solvent for the analyte species. The inert nature of the silicone minimizes the possibility of artifact formation, and the low pressure drop across the trap due to its open structure allows for a large volume flowrate of air to be drawn through the traps by means of a small, battery operated, portable pump. In contrast to packed bed traps, the low pressure drop of the open channels readily allow two traps to be coupled in series, in order to evaluate breakthrough of analytes from the first trap. As compared to SPME based methods, the larger volume of PDMS present in the sampling traps used in our study allows for larger sampling volumes and therefore potential improvements to the detection limits of the method.

LIF is then employed to selectively excite the PAH(s) of interest on the trap, and the resulting fluorescence is determined at the wavelength characteristic of the target $\mathrm{PAH}$. The technique may employ a number of excitation wavelengths, allowing for improved selectivity and the detection of three-membered ring structures due to the use of shorter excitation wavelengths than that provided by a nitrogen laser (337.1 nm).

Three PAHs were chosen as the focus for this work, based on their concentrations and ubiquity in the environment, as well as the environmental concerns associated with them. Naphthalene (Naph), phenanthrene (PhA) and pyrene (Py) were therefore identified from the US EPA list of 16 priority PAHs as suitable test analytes. Although the smaller PAHs have lower carcinogenic properties than benzo(a)pyrene, for example, which has a toxic equivalency factor of 1 as compared to that of 0.001 for the three PAHs of interest in this study (Nisbet and LaGoy, 1992), they are the most abundant PAHs in the urban atmosphere and they may react with other pollutants to form more toxic derivatives (Odabasi et al., 1999). It has been found that the carcinogenicity of indoor air may be dominated by naphthalene, where concentrations of $1100 \mathrm{ng} \mathrm{m}^{-3}$ have been reported, thus the use of naphthalene as a surrogate compound for PAH mixtures in indoor air has been suggested (Ohura et al., 2004). Semi-rural ambient gas phase concentrations of naphthalene of $13.1-45.2 \mathrm{ng} \mathrm{m}^{-3}$ and urban levels of 70.2-167.4 $\mathrm{ng} \mathrm{m}^{-3}$ have been reported (Temime-Roussel et al., 2004).

The work presented here focuses on the initial LIF method development and optimization thereof with respect to these PAHs.

\section{Materials and methods}

\subsection{Multi-channel silicone rubber traps and gas standards}

Traps which had been originally designed for solventless GC-MS analysis of environmental air and water samples (Ortner and Rohwer, 1996) were modified only by replacing the outer borosilicate glass sleeve by one made of UV-transparent quartz. The traps contained 22 internal silicone tubes, each $5.5 \mathrm{~cm}$ long (Sil-Tec, Technical Products, USA).

A diffusion tube assembly was employed which consisted of a glass vessel (4.5 $\mathrm{cm}$ long, $8 \mathrm{~mm}$ i.d.) containing naphthalene (Fluka, 99.8\% purity, GC grade), which was attached to a glass capillary ( $3.5 \mathrm{~cm}$ long, $6 \mathrm{~mm}$ i.d.) by means of a ground glass joint. The diffusion tube was allowed to equilibrate under temperature controlled conditions, and the diffusion rate $\left(2 \mathrm{ng} \mathrm{s}^{-1}\right)$ was determined gravimetrically (Barratt, 1981). The diffusion tube was placed in a glass diffusion chamber with inlet and outlet ports, which comprised two portions joined by a tightly sealed ground glass joint. A battery operated portable sampling pump was used to draw clean air into the sample holder and then onto the silicone rubber trap, as shown in Fig. 1.

\subsection{LIF instrumentation}

An excimer laser (Lambda Physik EMG201) was used to optically pump a dye laser (Rhodamine 6G, Lambda Physik). An intra-cavity grating allowed for wavelength tuneability over the gain bandwidth of the dye, and ensured a narrow bandwidth output $\left(0.1 \mathrm{~cm}^{-1}\right.$ at $\left.495 \mathrm{~nm}\right)$. The $584 \mathrm{~nm}$ output beam was frequency doubled through second harmonic generation in a non-linear crystal (BBO), resulting in the desired $292 \mathrm{~nm}$ excitation laser wavelength (absorption maximum for naphthalene) with a pulse energy of roughly $500 \mu \mathrm{J}$ in a $30 \mathrm{~ns}$ pulse. The unconverted pump wavelength was filtered out using a prism arrangement. The $292 \mathrm{~nm}$ laser beam was directed onto the silicone rubber trap without any focusing elements resulting in a roughly $5 \mathrm{~mm}$ diameter spot at the trap. The resulting fluorescence was optically collected with a plano-convex lens $(f=75 \mathrm{~mm})$, and resolved with a scanning double monochromator (Kratos, Schoeffel Instruments) equipped with a photomultiplier tube. Results were recorded on a PC linked to an oscilloscope (Tektronix TDS 360).

\subsection{TD-GC-MS analytical procedure}

Silicone rubber traps were thermally desorbed using a thermal desorber system (TDS) (Gerstel TDS 3) and the desorbed analytes were cryogenically focused via a cooled injection system (CIS). The traps were desorbed from $0{ }^{\circ} \mathrm{C}(0.5 \mathrm{~min})$ to $270{ }^{\circ} \mathrm{C}(2 \mathrm{~min})$ at $120^{\circ} \mathrm{C} \mathrm{min}^{-1}$ in the solvent vent mode $\left(100 \mathrm{ml} \mathrm{min}^{-1}\right.$ until $0.1 \mathrm{~min}$ ). Cryo-focusing of the $\mathrm{PAHs}$ was achieved using liquid nitrogen at $-40^{\circ} \mathrm{C}$ followed by rapid heating at $12{ }^{\circ} \mathrm{C} \mathrm{s}^{-1}$ to $300{ }^{\circ} \mathrm{C}(1 \mathrm{~min})$. The GC-MS system was an Agilent GC 7890A coupled to a Hewlett Packard 5975 inert XL EI/CI mass selective detector (MSD). The GC inlet was in the split mode with helium (Ultra High Purity, Afrox) as the inlet gas. An Agilent HP5 $(30 \mathrm{~m} \times 250 \mu \mathrm{m} \times 0.25 \mu \mathrm{m}) \mathrm{GC}$ column was used and the column head pressure was $68.8 \mathrm{kPa}$ using helium as the carrier gas. The total flowrate of the gas was $40.3 \mathrm{ml} \mathrm{min}^{-1}$ for a split ratio of $30: 1$, where the split flow was $39 \mathrm{ml} \mathrm{min}^{-1}$, thus the flowrate through the column was $1.3 \mathrm{ml} \mathrm{min}^{-1}$ at $40{ }^{\circ} \mathrm{C}$. The GC oven was temperature programmed from $40^{\circ} \mathrm{C}(1.5 \mathrm{~min})$ at $20^{\circ} \mathrm{C} \mathrm{min}{ }^{-1}$ to $150{ }^{\circ} \mathrm{C}(0 \mathrm{~min})$ and at $50{ }^{\circ} \mathrm{C} \mathrm{min}^{-1}$ to $300{ }^{\circ} \mathrm{C}(0 \mathrm{~min})$. The total run time was $20 \mathrm{~min}$. The GC-MS transfer line was at $300^{\circ} \mathrm{C}$, the mass scan range was 80-250 atomic mass units (amu), the solvent delay $6.8 \mathrm{~min}$, and the electron multiplier voltage was $\sim 1070 \mathrm{~V}$.

\subsection{Repeatability}

\subsubsection{Variations in detector response to blank trap signals}

Fluorescence spectra of seven blank multi-channel silicone rubber traps were recorded from 290 to $470 \mathrm{~nm}$, with $292 \mathrm{~nm}$ excitation, and the energy of the incident beam was measured by means an energy meter (Gentec). These experiments were conducted over two days, with one trap being analysed on both days for comparative purposes.

\subsubsection{Variations in detector response to similarly loaded traps}

A conditioned multi-channel silicone rubber trap was loaded with naphthalene from the diffusion tube for a period of $5 \mathrm{~min}$, at a flowrate of $484 \mathrm{ml} \mathrm{min}^{-1}$. The diffusion tube was disconnected from the trap, which was then positioned in the LIF excitation beam. The resulting fluorescence at $323 \mathrm{~nm}$ was recorded for $60 \mathrm{~s}$, after which the energy of the incident radiation was measured at the trap location. This experiment was then repeated with two other conditioned traps.

2.4.3. Variations in detector response due to slight variations in a loaded trap positioning

A multi-channel silicone rubber trap was loaded with naphthalene from the diffusion tube for an extended period (breakthrough conditions), and was then positioned in the LIF excitation beam. The oscilloscope signal was recorded at $323 \mathrm{~nm}$ for $60 \mathrm{~s}$, and the trap was then removed from the laser beam (which continued to fire) for a period of approximately $60 \mathrm{~s}$. The trap was then re-positioned in the laser beam and measurements were resumed for approximately $60 \mathrm{~s}$ This process of measurement and re-positioning was repeated a number of times.

\subsection{Sensitivity}

\subsubsection{LIF derived limit of detection}

A silicone rubber trap which was positioned in the laser system was loaded with naphthalene from the diffusion tube at a flowrate of $486 \mathrm{ml} \mathrm{min}^{-1}$, until equilibrium had been reached at the entrance end of the silicone tubes (at $50 \mathrm{~s}$ ) whilst the $323 \mathrm{~nm}$ fluorescence emission was recorded. 


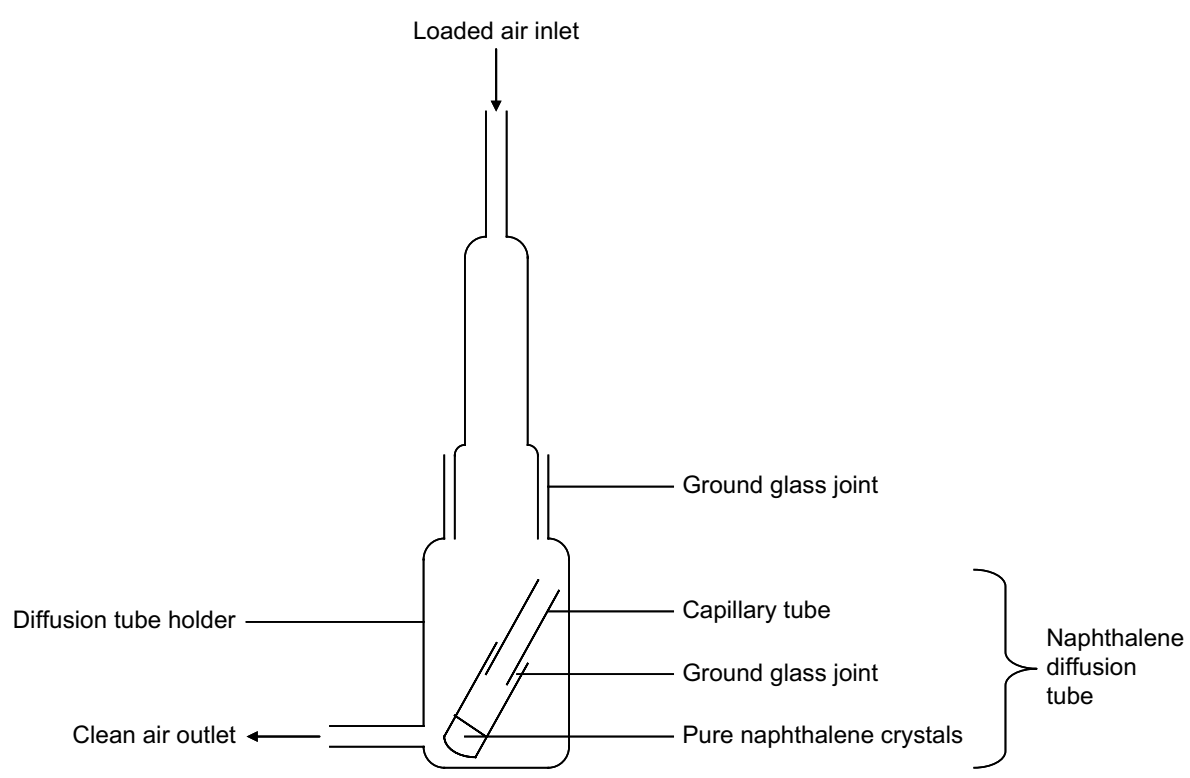

Fig. 1. Naphthalene diffusion tube inside the diffusion tube holder.

\subsubsection{Breakthrough volume}

In order to determine the breakthrough volume (Baltussen et al., 1997) two multi-channel silicone rubber traps were placed in series (primary and secondary or backup trap). A portable Gilair pump was used to draw air at $495 \mathrm{ml} \mathrm{min}^{-1}$ through the naphthalene diffusion tube and then through the two traps. The excitation beam was focused on the inlet side of the secondary trap, and the $323 \mathrm{~nm}$ fluorescence emission was recorded. After $2 \mathrm{~h}$, the pump was switched off, and an emission spectrum was obtained of each trap. Both traps were then capped and analysed by TD-GC-MS.

\subsubsection{Excitation of other PAHs of interest utilizing $292 \mathrm{~nm}$ excitation}

Two multi-channel silicone rubber traps were loaded with $250 \mathrm{ng}$ of pyrene and 240 ng of phenanthrene respectively, by means of a gas chromatographic collection similar to that reported for aroma fraction collection (Naudé et al., 2009). LIF analysis of each loaded trap was performed in the same manner as for naphthalene, with $292 \mathrm{~nm}$ incident radiation and the fluorescence scan was recorded from 295 to $465 \mathrm{~nm}$ (Py) or from 295 to $480 \mathrm{~nm}$ (PhA). The traps were then end capped, wrapped in aluminium foil and refrigerated prior to TD-GC-MS analysis.

\subsection{Photodegradation}

\subsubsection{Photodegradation of naphthalene as determined by LIF}

Naphthalene was loaded onto a silicone rubber trap from the diffusion tube, after a blank trap spectrum had been recorded. The pump was switched off after equilibrium conditions (constant [PAH]) had been established on the sample spot at the top of the trap, as evidenced by a stable oscilloscope signal, which was obtained with the monochromator set to $323 \mathrm{~nm}$. The laser continued to provide excitation radiation, and the consequent change in oscilloscope signal was recorded for a period of at least $10 \mathrm{~min}$. The laser light intensity was approximately $204 \mathrm{~W} \mathrm{~m}^{-2}$ (assuming operation at $8 \mathrm{~Hz}, 500 \mu \mathrm{J}$ and a $5 \mathrm{~mm}$ spot diameter). The experiment was conducted on different days, with different silicone rubber traps and slightly different incident laser pulse energies.

\subsubsection{Photodegradation of phenanthrene as determined by LIF}

Approximately $200 \mathrm{ng}$ of phenanthrene was loaded onto a silicone rubber trap by means of gas chromatographic loading. The change in oscilloscope signal at $364 \mathrm{~nm}$ was recorded over an irradiation period of $30 \mathrm{~min}$. The laser light intensity was approximately $41 \mathrm{~W} \mathrm{~m}^{-2}$ (assuming operation at $100 \mu \mathrm{J}$ ).

A LIF scan was recorded at the start of the experiment and again after the $30 \mathrm{~min}$ irradiation interval. The trap was then end capped, wrapped in aluminium foil and refrigerated prior to TD-GC-MS analysis.

\subsubsection{Identification of photodegradation products}

Photodegradation products were tentatively identified by means of NIST library searches of the TD-GC-MS results. No comparison to standards or quantitation was performed. Six traps which contained naphthalene, three traps loaded with phenanthrene, three traps which contained pyrene, and one trap loaded with both phenanthrene and pyrene were analysed by TD-GC-MS after LIF exposure for various time periods and for different incident energies. The CIS split ratio was varied between 10:1 and 100:1, depending on the concentration of analytes loaded onto the trap.

\section{Results and discussion}

\subsection{Repeatability}

The average fluorescence signal for different blank traps at $323 \mathrm{~nm}$, which is of interest with respect to naphthalene analyses, varied by less than the incident laser energy over the course of the experiments (RSD of $9.3 \%$ as compared to $14.7 \%, n=8$ with each blank trap oscilloscope reading being an average over eight laser pulses), therefore the latter would dominate in variations in fluorescence signals between traps. Similarly, the variation in incident laser energy was greater than that of the oscilloscope signal (RSD of $18.1 \%$ as compared to $12.4 \%, n=3$ ) for traps which had been loaded in the same manner.

The results of the experiment to determine the effect of variations in loaded trap positioning are shown in Fig. 2, where the fluorescence signal at $323 \mathrm{~nm}$ varied by $4.5 \%$, whilst the incident laser energy varied by $14.8 \%$. The slight decrease in fluorescence signal towards the end of the experiment would most likely have arisen due to the decrease in laser energy, as well as from volatilization and photodegradation losses of naphthalene from the trap. Slight variations in the positioning of the trap therefore did not appear to result in significant variations in the oscilloscope signal.

\subsection{Sensitivity}

Fig. 3 shows the $323 \mathrm{~nm}$ fluorescence emission which was recorded over a period of time during naphthalene diffusion tube loading at a diffusion rate of $\sim 2 \mathrm{ng} \mathrm{s}^{-1}$. Equilibrium conditions were obtained for the analysed sample spot within $\sim 16 \mathrm{~s}$ (each data point is an average over 8 laser pulses). The noise $(0.001 \mathrm{~V})$ was calculated from the root mean square (RMS) value of the data points post equilibrium, as there were statistically insufficient data points in the region prior to the signal increase, and it was found that the RMS values were in fact the same for both regions. The voltage at equilibrium averaged $0.873 \mathrm{~V}$, thus the signal: noise ratio was $873: 1$ for a diffusion rate of $\sim 2 \mathrm{ng} \mathrm{s}^{-1}$ and operation at $\sim 500 \mathrm{ml} \mathrm{min}{ }^{-1}$. For a signal:noise ratio of $3: 1$, a diffusion rate of 


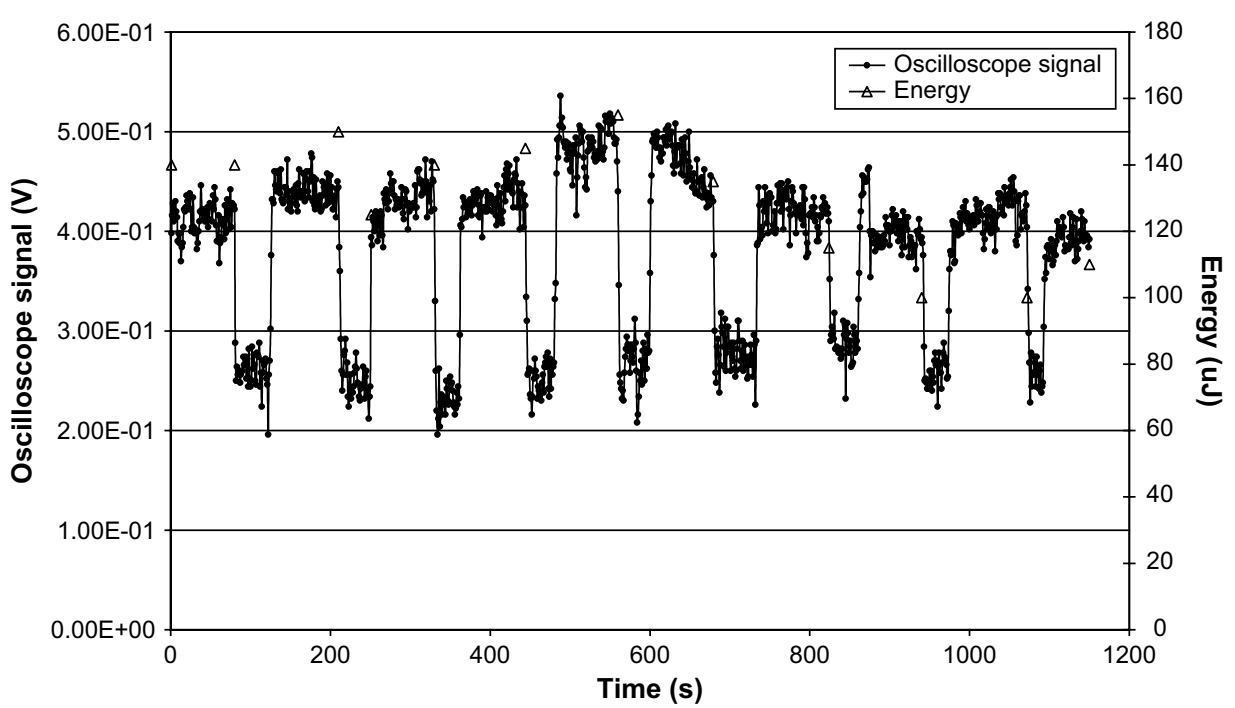

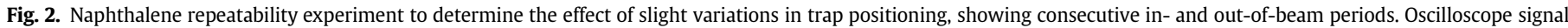
measured at $323 \mathrm{~nm}$. No re-loading of the trap during out-of-beam periods was performed.

$\sim 7 \mathrm{pg} \mathrm{s}^{-1}$ at this flowrate could therefore be used, which equates to a limit of detection of $\sim 1 \mu \mathrm{g} \mathrm{m}{ }^{-3}$, which is suitable for impacted environments, including workplace exposure.

The TD-GC-MS results after $2 \mathrm{~h}$ loading from the diffusion tube were $9507 \mathrm{ng}$ for the primary trap and $9245 \mathrm{ng}$ for the secondary trap, which indicated that the secondary trap had also reached equilibrium conditions. A total of 14,400 ng of naphthalene should have loaded on the traps, using a diffusion rate of $2 \mathrm{ng} \mathrm{s}^{-1}$, which is lower than the total concentration obtained by TD-GC-MS $(18,752 \mathrm{ng})$. This is most likely due to thermal desorption effects, which are under further investigation. The LIF scans of the primary and secondary traps post loading also indicated a similar naphthalene concentration in agreement with the TD-GC-MS results.

A breakthrough volume of $\sim 41$ was estimated for $10 \%$ breakthrough of naphthalene, which relates to a sampling interval of $\sim 8 \mathrm{~min}$ at $500 \mathrm{ml} \mathrm{min}^{-1}$. The GC-MS can detect $1 \mathrm{pg}$ with a signal to noise ratio of $400: 1$ in TIC mode, according to the instrument specifications, which would equate to a detection limit of $\sim 0.3 \mathrm{ng} \mathrm{m}^{-3}$ for this breakthrough volume.

It was found that $292 \mathrm{~nm}$ was not a suitable excitation wavelength for pyrene at these levels, although a higher incident energy may have improved the response obtained. A well resolved fluorescence emission spectrum was, however, obtained for $\sim 240 \mathrm{ng}$ of phenanthrene (Fig. 4), which indicated that $292 \mathrm{~nm}$ excitation may also be useful for the analysis of this PAH, whilst selectivity can be provided by the monochromator for samples containing mixtures of PAHs. A limit of detection for phenanthrene was not determined.

\subsection{Photodegradation}

PAHs are known to photodegrade under environmental conditions (Kamens et al., 1990), although the rate at which this occurs is dependant on many factors, including the nature of the surface onto which they are absorbed. A decrease in naphthalene

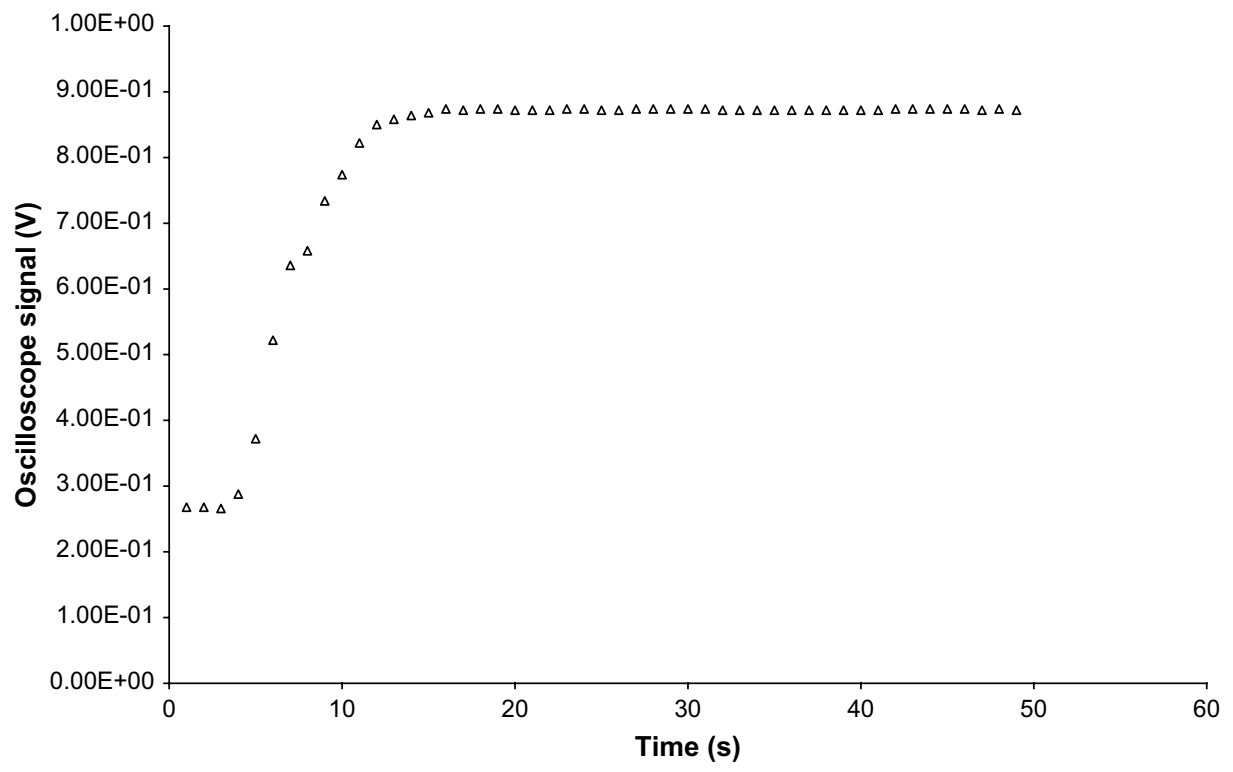

Fig. 3. Fluorescence signal at $323 \mathrm{~nm}$ (naphthalene emission) as a function of time at a sample spot at the entrance of the trap with $292 \mathrm{~nm}$ excitation. 


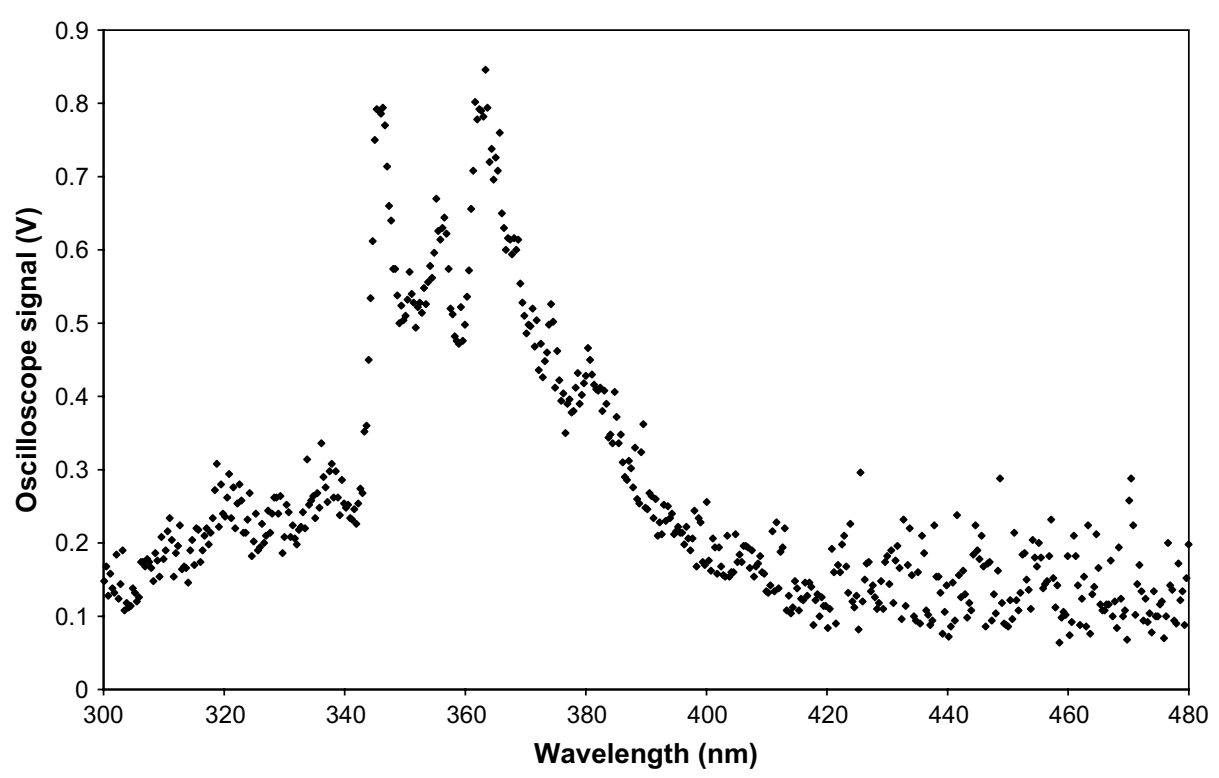

Fig. 4. Fluorescence spectrum of $240 \mathrm{ng}$ of phenanthrene loaded onto a multi-channel silicone rubber trap, with $292 \mathrm{~nm}$ excitation and $140 \mu \mathrm{J}$ incident energy.

fluorescence signal was observed upon continued irradiation after equilibrium conditions had been established. A linear trendline was fitted to the degradation portion of each of the data sets (an example is shown in Fig. 5), and the equations of these lines were used to determine average oscilloscope intensities after different time intervals. The rate of degradation (which may also have included some volatilization losses) was found to be similar in each case ( $12.4 \% \mathrm{RSD}, n=3$ ) and the decrease in signal over a 5 min time interval, which is representative of a typical PAH LIF scan, was approximately $10 \%$, and the half-life was $\sim 35 \mathrm{~min}$. Single wavelength detection can be performed in a fraction of this time, therefore the loss was considered to be acceptable.

A decrease in fluorescence signal was found for phenanthrene during a $30 \mathrm{~min}$ irradiation period, as shown in Fig. 6, and a decrease in PhA fluorescence was also noted upon comparison of the LIF scans obtained before and after the 30 min irradiation period. $117 \mathrm{ng}$ of phenanthrene was found to be present on the trap after the photodegradation experiment by TD-GC-MS analysis, which relates to $\sim 42 \%$ loss. The oscilloscope signal at $364 \mathrm{~nm}$ (PhA fluorescence emission maximum) obtained from the LIF scans also decreased by $44 \%$ after the irradiation period. A $17 \%$ decrease in oscilloscope signal would be expected for a 5 min LIF scan, and the PhA half-life was found to be $\sim 30 \mathrm{~min}$. This compares well to the decrease in oscilloscope signal measured after the 30 min irradiation period and to the TD-GC-MS results.

The photodegradation products, as determined by TD-GC-MS were generally present at very low levels, thus the library matches were not very good in some cases, although they do provide an indication of possible breakdown products. Five of the six traps which had been loaded with naphthalene were found to contain

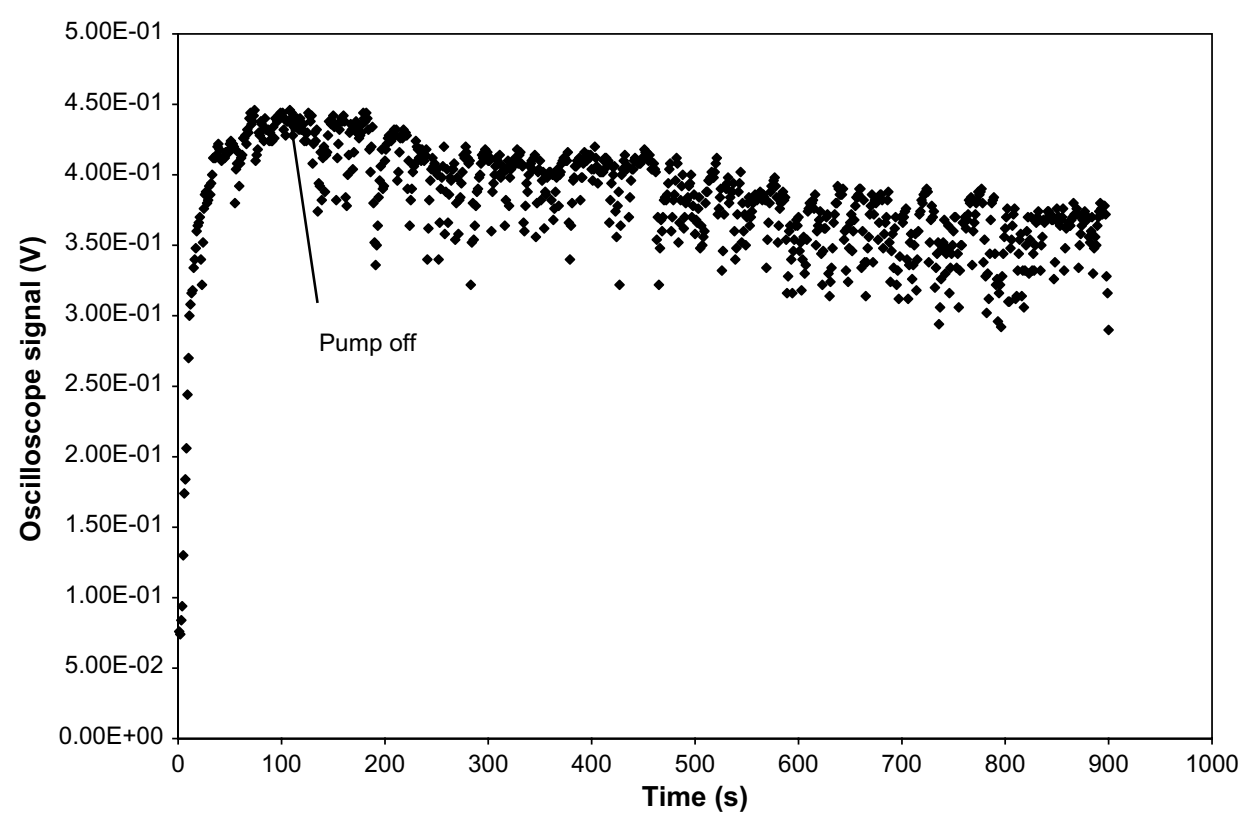

Fig. 5. Degradation in the naphthalene oscilloscope signal upon continued laser irradiation ( $150 \mu \mathrm{J}$ incident energy). 


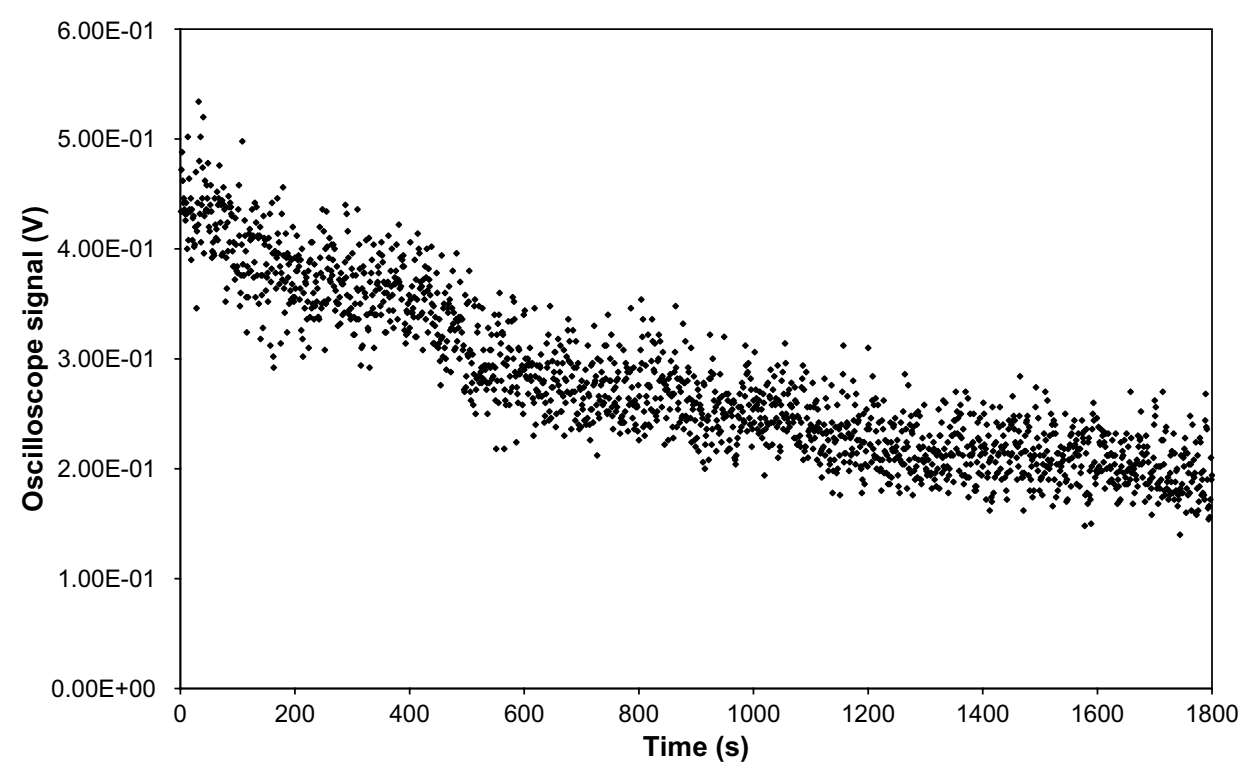

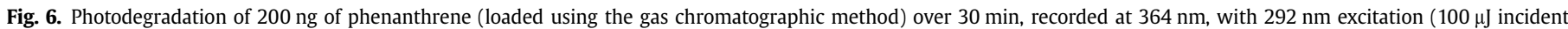
energy).

phenol, whilst four contained both benzyl alcohol and phthalic anhydride. Benzaldehyde, benzoic acid, and benzyl formate were also found in some cases. No breakdown products were found in a naphthalene trap which had only been exposed for $5 \mathrm{~min}$ (a typical LIF scan period), even though it contained a high concentration of naphthalene, and the laser energy was comparable to that of other LIF analyses where degradation products were detected.

Benzyl alcohol and phthalic anhydride were present on two of the three phenanthrene containing traps, whilst benzyl formate and phenol were also detected in some cases. Fewer degradation products were found in the traps loaded with pyrene, although exposure times were all relatively short (10 min). Benzyl alcohol was present on two of the traps, whilst acetophenone, benzyl formate, and phthalic anhydride were each found on one trap. Phenol, benzaldehyde, and benzyl alcohol were identified on the trap which had been loaded with both phenanthrene and pyrene.

The effect of the photodegradation products (particularly the organic acids) was also visible, in that column bleed was evident in the chromatograms, due to breakdown of the stationary phase by these acidic compounds.

Naphthalene and phenanthrene therefore formed similar oxidative photodegradation products and also had similar rates of photodegradation. The latter were higher than that reported in most other studies, such as that of PAHs adsorbed onto pine needles, where photolytic half-lives were $>12 \mathrm{~h}$ with $450 \mathrm{Wm}^{-2}$ irradiation by sunlight (Wang et al., 2005). This is to be expected as LIF involves single wavelength irradiation at or close to the analyte's absorption maximum. Shorter half-lives (for example, $28 \mathrm{~min}$ for phenanthrene) have been reported for PAHs adsorbed onto maize leaves at $<24 \mathrm{~W} \mathrm{~m}^{-2}$ with $355-375 \mathrm{~nm}$ irradiation (Wild et al., 2005).

Once the LIF photodegradation rate has been determined for the target $\mathrm{PAH}(\mathrm{s})$ at the experimental wavelength concerned, it is possible to correct for the resulting decrease in analyte concentration upon subsequent quantitative analysis of samples by TD-GC-MS.

\section{Conclusions}

The method described has the potential to serve as a means to avoid the comprehensive analysis of samples which do not contain appreciable levels of PAHs. The LIF experimental procedure is simple and rapid, with acceptably low limits of detection, even with the initial, unoptimized optical arrangement and without extensive time-averaging. LIF also provides selectivity without the need for sample clean-up and separation processes, which may entail the use of organic solvents and cryogenic equipment.

The method is basically non-destructive and the sample traps may be subsequently analysed directly by TD-GC-MS. The method developed here may therefore find application in the analysis of combustion products arising from incineration; veld fires; sugar cane burning; and diesel fuel combustion.

Further development and optimization of the method is needed in order to ensure its robustness and to provide sufficiently accurate and reproducible results. Specifically the variation in incident energy provided by the laser system should be minimized, signal averaging and collection and detection of fluorescence emission should be optimized, and the capability of the system to resolve the PAH emission spectra in mixtures should be investigated.

\section{Acknowledgements}

Funding provided by the CSIR, NLC and NRF is acknowledged. Andreas Trüe and Henk van Wyk are thanked for their assistance with the TD-GC-MS analyses and LIF setup, respectively.

\section{References}

Allain, L.R., Stratis, D.N., Cullum, B.M., Mobley, J., Hajaligol, M.R., Vo-Dinh, T., 2003 Real-time detection of PAH mixtures in the vapor phase at high temperatures. Journal of Analytical and Applied Pyrolysis 66, 145-154.

Baltussen, E., Janssen, H.-G., Sandra, P., Cramers, C.A., 1997. A new method for sorptive enrichment of gaseous samples: application in air analysis and natura gas characterization. Journal of High Resolution Chromatography 20, 385-393.

Barratt, R.S, 1981. The preparation of standard gas mixtures. The Analyst 106 (1265) 817-849.

Chi, Z., Cullum, B.M., Stokes, D.L., Mobley, J., Miller, G.H., Hajaligol, M.R., Vo-Dinh, T., 2001. Laser-induced fluorescence studies of polycyclic aromatic hydrocarbons (PAH) vapors at high temperatures. Spectrochimica Acta Part A 57, 1377-1384.

Grundl, T.J., Aldstadt, J.H., Harb, J.G., St Germain, R.W., Schweitzer, R.C., 2003. Demonstration of a method for the direct determination of polycyclic aromatic hydrocarbons in submerged sediments. Environmental Science and Technology 37 (6), 1189-1197.

Hawthorne, S.B., St. Germain, R.W., Azzolina, N.A., 2008. Laser-induced fluorescence coupled with solid-phase microextraction for in situ determination of PAHs in 
sediment pore water. Environmental Science and Technology 42 (21), 8021 8026.

Kamens, R.M., Guo, J., Guo, Z., McDow, S.R., 1990. Polynuclear aromatic hydrocarbon degradation by heterogeneous reactions with $\mathrm{N}_{2} \mathrm{O}_{5}$ on atmospheric particles. Atmospheric Environment 24(A) (5), 1161-1173.

Kotzick, R., Niessner, R., 1996. Application of time-resolved, laser-induced and fiberoptically guided fluorescence for monitoring of a PAH-contaminated remediation site. Fresenius Journal of Analytical Chemistry 354, 72-76.

Koziel, J.A., Odziemkowski, M., Pawliszyn, J., 2001. Sampling and analysis of airborne particulate matter and aerosols using in-needle trap and SPME fiber devices. Journal of Analytical Chemistry 73, 47-54.

Knorr, F.J., Harris, J.M., 1981. Resolution of multicomponent fluorescence spectra by an emission wavelength-decay time data matrix. Analytical Chemistry 53, 272-276.

Martinez, M., Harder, H., Ren, X., Lesher, R.L., Brune, W.H., 2004. Measuring atmospheric naphthalene with laser-induced fluorescence. Atmospheric Chemistry and Physics 4, 563-569.

Naudé, Y., van Aardt, M., Rohwer, E.R., 2009. Multi-channel open tubular traps for headspace sampling, gas chromatographic collection and olfactory assessment of milk volatiles. Journal of Chromatography A 1216 (14), 2798-2804.

Nisbet, I.C.T, LaGoy, P.K., 1992. Toxic equivalency factors (TEFs) for polycyclic aromatic hydrocarbons (PAHs). Regulatory Toxicology and Pharmacology 16, 290-300.

Odabasi, M., Vadar, N., Sofuoglu, A., Tasdemir, Y., Holsen, T.M., 1999. Polycyclic aromatic hydrocarbons (PAHs) in Chicago air. The Science of the Total Environment 227, 57-67.

Odziemkowski, M., Koziel, J.A., Irish, D.E., Pawliszyn, J., 2001. Sampling and Raman confocal microspectroscopic analysis of airborne particulate matter using poly(dimethylsiloxane) solid-phase microextraction fibres. Analytical Chemistry 73, 3131-3139.

Ohura, T., Amagai, T., Fusaya, M., Sugiyama, T., Matsushita, H., 2004. Characteristics of particle matter and associated polycyclic aromatic hydrocarbons in indoor and outdoor air in two cities in Shizuoka, Japan. Environmental Science and Technology 38, 2045-2054.

Ortner, E.K., August, 1994, Alternative concentration techniques for the trace analysis of semi-volatile organic air pollutants by capillary gas chromatography, MSc thesis, University of Pretoria.

Ortner, E.K., Rohwer, E.R., 1996. Trace analysis of semi-volatile organic air pollutants using thick film silicone rubber traps with capillary gas chromatography. Journal of High Resolution Chromatography 19, 339-344.

Song, J.M., Jagannathan, R., Stokes, D.L., Vo-Dinh, T., Hajaligol, M.R., 2003. Real-time monitoring of polycyclic aromatic hydrocarbons in cigarette smoke using time-resolved laser-induced fluorescence. Polycyclic Aromatic Compounds 23, 429-439.

Temime-Roussel, B., Monod, A., Massiani, C., Wortham, H., 2004. Evaluation of annular denuder tubes for atmospheric PAH partitioning studies - 1: evaluation of the trapping efficiency of gaseous PAHs. Atmospheric Environment 38, 1913-1924.

Wang, D., Chen, J., Xu, Z., Qiao, X., Huang, L., 2005. Disappearance of polycyclic aromatic hydrocarbons sorbed on surfaces of pine [Pinua thunbergii] needles under irradiation of sunlight: volatilization and photolysis. Atmospheric Environment 39, 4583-4591.

Wauters, E., Van Caeter, P., Desmet, G., David, F, Devos, C., Sandra, P. 2008 Improved accuracy in the determination of polycyclic aromatic hydrocarbons in air using $24 \mathrm{~h}$ sampling on a mixed bed followed by thermal desorption capillary gas chromatography-mass spectrometry. Journal of Chromatography A 1190, 286-293.

Wild, E., Dent, J., Thomas, G.O., Jones, K.C., 2005. Real-time visualization and quantification of PAH photodegradation on and within plant leaves. Environmental Science and Technology 39, 268-273.

Wild, E., Dent, J., Thomas, G.O., Jones, K.C., 2007. Use of two-photon excitation microscopy and autofluorescence for visualizing the fate and behavior of semivolatile organic chemicals within living vegetation. Environmental Toxicology and Chemistry 26 (12), 2486-2493. 